\title{
DETERMINANTS OF ENVIRONMENTAL DOMAIN OF QUALITY OF LIFE IN ECONOMICALLY ACTIVE POPULATION LIVING IN SILESIAN AGGLOMERATION, POLAND
}

\author{
MAŁGORZATA KOWALSKA ${ }^{1}$, FELIX DANSO², MARIA HUMENIUK², ELŻBIETA KUŁAK², \\ and HUBERT ARASIEWICZ ${ }^{2}$ \\ ${ }^{1}$ Medical University of Silesia, Katowice, Poland \\ Department of Epidemiology \\ ${ }^{2}$ Medical University of Silesia, Katowice, Poland \\ Students' Scientific Society at the Department of Epidemiology
}

\begin{abstract}
Objectives: The aim of this paper is to identify the factors that determine the environmental domain of quality of life in economically active adults living in the industrial agglomeration in Poland. Materials and Methods: During the crosssectional epidemiological study conducted among the economically active population aged 45-60, we used a short version of the WHOQOL-BREF questionnaire. Respondents were recruited randomly from selected factories located in the Silesian Agglomeration. The statistical analysis used descriptive and analytical methods available in the Statistica 9.0 software. Results: The results confirmed the statistically significant association between marital status, type of occupational activity, declared health status, and the environmental domain of quality of life in economically active inhabitants of the Silesian Agglomeration. The best qualities of life in the environmental domain were those of married people, white collars, and persons who declared their health status to be the best. Conclusions: The major determinants of environmental quality of life in economically active population living in the industrial agglomeration include non-occupational factors, such as marital status and current health status, while a significantly better quality of life was associated with being a white-collar worker and not living in the vicinity of the road with heavy traffic. The results may be useful for future planned activities intended to improve the health and the quality of working life.
\end{abstract}

Key words:

Cross-sectional study, Quality of life, WHOQOL-BREF questionnaire

\section{INTRODUCTION}

Quality of life is defined as "an individual's perception of their position in life in the context of the culture and value systems in which they live and in relation to their goals, expectations, standards, and concerns" [1,2].
The definition highlights quality of life as an effect of complex way the interviewed person perceives his/her physical health, psychological state, level of independence, social relationships, personal beliefs, and his/her relationship with the environment. The environmental domain of life

The study was supported by the Medical University of Silesia (Grant: KNW-2-039/10).

Received: September 9, 2011. Accepted: June 28, 2012.

Corresponding author: M. Kowalska, Department of Epidemiology, Medical University of Silesia, Medyków 18, 40-752 Katowice, Poland (e-mail: mkowalska@sum.edu.pl). 
embraces such aspects of life as safety, financial situation, the ability to pursue one's interests, housing, health care facilities, and communications.

Recent literature data suggest that the quality of life and health of urban dwellers depends significantly on the quality of the urban environment, including quality of air and drinking water, functioning in a complex system of interactions with social, economic and cultural factors [3]. Typically, the quality of life is assessed using standard research questionnaires [4]. The WHOQOL-BREF questionnaire developed by the World Health Organization to allow the simultaneous assessment of quality of life in the somatic, social, environmental and psychological domains is a good example [5]. The aim of this paper is to identify the factors which contribute to a better environmental domain quality of life in economically active adults living in the industrial agglomeration in Poland. Lack of such data relating to the environmental domain of quality of life in Poland justifies the present study.

\section{MATERIALS AND METHODS}

During the cross-sectional epidemiological study conducted among the economically active population of the Silesian Agglomeration, we used a short version of the WHOQOL-BREF questionnaire (licensed and permitted by the relevant ethical committee). In addition, the questionnaire contains 13 questions identifying demographic data (gender, age, marital status, educational level, type of occupational activity) as well as data on various individual exposures (smoking, place of residence, respiratory or cardiovascular disease). Selection of independent variables describing health status of workers were dictated by the study protocol and focused on assessing the environmental impact of residence on the quality of life. Respondents were persons aged 45-60 years, recruited from selected factories located in the Silesian Agglomeration. Respondents included employees of the mining industry, large industrial and service enterprises within the Silesian Agglomeration, as well as government and contractual educational sector employees.

The study participants included 1029 subjects residing in the Silesia region and the frequency of response was evaluated for each questionnaire, and raw scores obtained in response to the evaluation of the specified sphere of environmental quality of life were summarised. A total number of 1128 questionaires were collected, while 99 were excluded because of missing data (no answers to some questions). According to the WHO protocols, we included into the analysis only the questionnaires with complete answers about the quality of life. The environmental domain of quality of life was assessed from the total points scored for the answers to the following questions:

- Q8: How safe do you feel in your daily life?

- Q9: How healthy is your physical environment?

- Q12: Do you have enough money to meet your needs?

- Q13: How available to you is the information that you need in your day-to-day life?

- Q14: To what extent do you have the opportunity for leisure activities?

- Q23: How satisfied are you with the conditions of your living place?

- Q24: How satisfied are you with your access to health services?

- Q25: How satisfied are you with your transport?

Keys to assess particular questions are contained in the instruction of the WHOQOL-BREF questionnaire. The raw scores were converted to a scoring scale ranging from 0 to 100 points as recommended by WHO [6].

\section{Statistics}

The statistical analysis used descriptive and analytical methods available in the Statistica 9.0 software. For quantitative variables, we calculated the mean value with its standard deviation (SD), median, range and percentile values. The association between specified quality of life 
and age, gender, education, type of occupational activity and living environment were assessed by chi ${ }^{2}$ test (for qualitative variables), U-Mann Whitney or ANOVA test (for quantitative variables).

The results of the simple analysis were verified by a multivariate analysis (multiple regression model). Analyses were conducted in two ways; first, we evaluated the impact of independent variables on self-declared particular questions assessing the environmental domain of quality of life (presented as qualitative variables in three categories: good, moderate, poor). We then evaluated the impact of independent variables on environmental quality of life expressed as a sum of points.

Model used in multivariative analysis was in the form: Total score $=\mathrm{b} 0+\mathrm{b} 1^{*}$ gender $+\mathrm{b} 22^{*}$ educational level + b3*type of occupational activity + b $4 *$ current smoking $+\mathrm{b} 5 *$ residence in the vicinity of the road with heavy traffic $+\mathrm{b} 6 *$ diagnosed respiratory or cardiovascular disease $+\mathrm{b} 77^{*}$ current health status. All applied tests were twosided. The level of statistical significance of the results was set at $\mathrm{p}<0.05$.

\section{RESULTS}

We examined 1029 economically active 45 to 60 years old subjects living in Silesian Agglomeration. The selected descriptive statistics of qualitative variable are presented in Table 1. The table shows the mean value and standard deviation, median and percentile values, and range of age, years of tobacco smoking and scores obtained for the evaluated quality of life domains.

The total number of points after the transformation of the raw score obtained for the assessed quality of life was $241 \pm 41.2$ out of 400 . The lowest scores were obtained for somatic and environmental domains, 54.4 \pm 9.9 and $57.6 \pm 14.6$ points, respectively.

The subjects were 684 women and 345 men; most of them were married ( $76.2 \%$ of respondents). The singles included: 74 never-married persons (7.1\%), 65 widowed people (6.3\%), 92 divorced (8.9\%) and 14 separated people (1.4\%). Over half of the respondents $(\mathrm{N}=549 ; 53.5 \%)$ reported average level of education (those with secondary education). Most respondents were white collar workers $(\mathrm{N}=621 ; 60.5 \%)$. Approximately, one-tenth of the subjects $(\mathrm{N}=153 ; 14.9 \%)$ declared exposure to air pollution at their workplace.

Half of the respondents (51.3\%) were former smokers, while one in four respondents $(25.3 \%)$ was current smoker. Nearly half of subjects reported that they lived in the vicinity of industrial plants that cause air pollution (48.3\%) and in the vicinity of the road with heavy traffic $(48.0 \%)$. Almost every fifth respondent (18.9\%) believes that the current job leads to a deterioration in health. Good health status was reported by $42.9 \%$ of subjects, while only $5.3 \%$

Table 1. Particular descriptive statistics for quantitative variables in study group

\begin{tabular}{lrrrrrc}
\hline \multicolumn{1}{c}{ Variable } & Mean \pm SD & Median & Min & Max & $\begin{array}{r}\text { Percentile } \\
33.33 \%\end{array}$ & $\begin{array}{c}\text { Percentile } \\
66.66 \%\end{array}$ \\
\hline Age (years) (N = 1029) & $51.0 \pm 4.5$ & 50.0 & 45.0 & 60.0 & 48.0 & 53.0 \\
Current tobacco smoking (years) (N = 260) & $22.4 \pm 9.4$ & 20.0 & 1.0 & 50.0 & 20.0 & 28.0 \\
Somatic domain of quality of life ( $=1029)$ & $54.4 \pm 9.9$ & 56.0 & 19.0 & 88.0 & 50.0 & 56.0 \\
Psychological domain of quality of life (N = 1029) & $60.8 \pm 11.4$ & 63.0 & 13.0 & 94.0 & 56.0 & 69.0 \\
Social domain of quality of life (N = 1029) & $68.3 \pm 16.4$ & 69.0 & 0.0 & 100.0 & 69.0 & 75.0 \\
Environmental domain of quality of life (N = 1029) & $57.6 \pm 14.6$ & 56.0 & 6.0 & 100.0 & 50.0 & 63.0 \\
Total score of quality of life ( $=1029)$ & $241.0 \pm 41.2$ & 244.0 & 76.0 & 350.0 & 225.0 & 262.0 \\
\hline
\end{tabular}


of respondents reported their health status as poor. Over half of the subjects $(64.3 \%)$ declared good or very good quality of life, while only 57 people (5.5\% of respondents) reported poor quality of life. Table 2 shows selected descriptive statistics for qualitative variables.

Table 2. Particular descriptive statistics for qualitative variables in the study group

\begin{tabular}{|c|c|c|}
\hline \multirow[t]{2}{*}{ Variable } & \multicolumn{2}{|c|}{$\begin{array}{c}\text { Chosen answers } \\
\text { to particular } \\
\text { questions }\end{array}$} \\
\hline & $\mathrm{n}$ & $\%$ \\
\hline \multicolumn{3}{|l|}{ Gender $(\mathrm{N}=1029)$} \\
\hline female & 684 & 66.5 \\
\hline male & 345 & 33.5 \\
\hline \multicolumn{3}{|l|}{ Marital status ( $\mathrm{N}=1029)$} \\
\hline non-married person & 245 & 23.8 \\
\hline married person & 784 & 76.2 \\
\hline \multicolumn{3}{|l|}{ Education level $(\mathrm{N}=1027)$} \\
\hline lower (primary or secondary) & 610 & 59.4 \\
\hline higher & 417 & 40.6 \\
\hline \multicolumn{3}{|c|}{ Type of occupational activity ( $\mathrm{N}=1027$ ) } \\
\hline white collar worker & 621 & 60.5 \\
\hline blue collar worker & 406 & 39.5 \\
\hline \multicolumn{3}{|l|}{ Ever tobacco smoking ( $\mathrm{N}=1029)$} \\
\hline yes & 531 & 51.6 \\
\hline no & 498 & 48.4 \\
\hline \multicolumn{3}{|c|}{ Current tobacco smoking $(\mathrm{N}=1029)$} \\
\hline yes & 260 & 25.3 \\
\hline no & 769 & 74.7 \\
\hline \multicolumn{3}{|c|}{$\begin{array}{l}\text { Declared residence in a neighborhood of } \\
\text { factories polluting the air }(\mathrm{N}=1029)\end{array}$} \\
\hline yes & 497 & 48.3 \\
\hline no & 409 & 39.7 \\
\hline don’t know & 123 & 11.9 \\
\hline \multicolumn{3}{|c|}{$\begin{array}{l}\text { Living in the vicinity of the road with heavy } \\
\text { traffic }(\mathrm{N}=1029)\end{array}$} \\
\hline yes & 494 & 48.0 \\
\hline no & 492 & 47.8 \\
\hline don't know & 43 & 4.2 \\
\hline \multicolumn{3}{|c|}{ Self-assessed current health status $(\mathrm{N}=1029)$} \\
\hline good & 442 & 42.9 \\
\hline moderate & 532 & 51.7 \\
\hline poor & 55 & 5.3 \\
\hline
\end{tabular}

Table 2. Particular descriptive statistics for qualitative variables in the study group - cont.

\begin{tabular}{lrr}
\hline \multicolumn{1}{c}{ Variable } & $\begin{array}{c}\text { Chosen answers } \\
\text { to particular } \\
\text { questions }\end{array}$ \\
\cline { 2 - 3 } & \multicolumn{1}{c}{$\mathrm{n}$} & $\%$ \\
\hline $\begin{array}{l}\text { Perception that current job results in } \\
\text { deterioration of health }(\mathrm{N}=1029)\end{array}$ & & \\
yes & 195 & 18.9 \\
no & 643 & 62.5 \\
don't know & 191 & 18.6 \\
Ever diagnosed respiratory or cardiovascular & & \\
$\quad$ disease $(\mathrm{N}=980)$ & & \\
yes & 415 & 42.3 \\
no & 565 & 57.7 \\
Declared quality of life $(\mathrm{N}=746)$ & & \\
good & 662 & 64.3 \\
moderate & 310 & 30.1 \\
poor & 57 & 5.5 \\
\hline
\end{tabular}

Quite a large proportion of respondents (42.3\%) had been in the past diagnosed with respiratory or cardiovascular disease. Most of them had hypertension (248 people), allergic rhinitis (88 people) and coronary heart disease (46 people) with only 69 subjects declaring at least two diseases.

Environmental domain of quality of life was calculated according to the WHOQOL-BREF questionnaire from the total of points obtained on the basis of responses to the following eight questions: Q8, Q9, Q12-Q14, Q23-Q25. Accurate data describing number and frequency of chosen answers are shown in Table 3.

Over half of the respondents $(53.4 \%)$ felt safe (mostly or completely) in their daily lives, only $1.8 \%$ of respondents did not feel safe. Only one third of subjects (34.3\%) believed that the environment promoted health. More than a quarter of respondents $(27.9 \%)$ declared that they received insufficient amount of money to meet their own needs. Similar percentage $(29.3 \%)$ of subjects declared financial satisfaction. Over half of the respondents $(54.1 \%)$ believed that they had sufficient access to information necessary 
Table 3. Number and proportion of respondents who have chosen one out of three prepared answers to questions included in WHOQOL-BREF questionnaire to assess the environmental domain of quality of life

\begin{tabular}{|c|c|c|}
\hline \multirow{2}{*}{ Question of WHOQOL-BREF } & \multicolumn{2}{|c|}{ Respondents } \\
\hline & $\mathrm{n}$ & $\%$ \\
\hline \multicolumn{3}{|l|}{ Q8: I feel safe in my daily life } \\
\hline $1=$ not at all or a little & 76 & 7.4 \\
\hline $2=$ moderately & 434 & 42.2 \\
\hline $3=$ very much or extremely & 519 & 53.4 \\
\hline \multicolumn{3}{|l|}{ Q9: My physical environment is healthy } \\
\hline $1=$ not at all or a little & 155 & 15.1 \\
\hline $2=$ moderately & 521 & 50.6 \\
\hline $3=$ very much or extremely & 353 & 34.3 \\
\hline \multicolumn{3}{|l|}{ Q12: Enough money to meet my needs } \\
\hline $1=$ not at all or a little & 287 & 27.9 \\
\hline $2=$ moderately & 440 & 42.8 \\
\hline $3=$ mostly or completely & 302 & 29.3 \\
\hline \multicolumn{3}{|c|}{$\begin{array}{l}\text { Q13: Available information that I need in my } \\
\text { day-to-day life }\end{array}$} \\
\hline $1=$ not at all or a little & 83 & 8.1 \\
\hline $2=$ moderately & 389 & 37.8 \\
\hline $3=$ mostly or completely & 557 & 54.1 \\
\hline \multicolumn{3}{|l|}{ Q14: The opportunity for leisure activities } \\
\hline $1=$ not at all or a little & 198 & 19.2 \\
\hline $2=$ moderately & 475 & 46.2 \\
\hline $3=$ mostly or completely & 356 & 34.6 \\
\hline \multicolumn{3}{|l|}{$\begin{array}{l}\text { Q23: Satisfaction with the conditions } \\
\text { of the living place }\end{array}$} \\
\hline $1=$ dissatisfied & 80 & 7.8 \\
\hline $2=$ neither satisfied nor dissatisfied & 191 & 18.6 \\
\hline $3=$ satisfied & 758 & 73.6 \\
\hline \multicolumn{3}{|l|}{$\begin{array}{l}\text { Q24: Satisfaction with the access to health } \\
\text { services }\end{array}$} \\
\hline $1=$ dissatisfied & 478 & 46.4 \\
\hline $2=$ neither satisfied nor dissatisfied & 397 & 38.6 \\
\hline $3=$ satisfied & 154 & 15.0 \\
\hline \multicolumn{3}{|l|}{ Q25: Satisfaction with transport } \\
\hline $1=$ dissatisfied & 290 & 28.2 \\
\hline $2=$ neither satisfied nor dissatisfied & 430 & 41.8 \\
\hline $3=$ satisfied & 309 & 30.0 \\
\hline
\end{tabular}

for everyday life. Only one in three respondents (34.6\%) declared that they were able to pursue their own interests. A relatively high percentage of subjects declared a sufficient degree of satisfaction with their housing conditions (73.6\% of respondents). Almost every second respondent (46.4\%) declared a low degree of satisfaction with health care providers. As much as $28.2 \%$ of the people were dissatisfied with the communal and public transportation system. Declarations of respondents on environmental domainrelated aspects of quality of life differed significantly with respondents' gender, educational level, marital status, health condition, life style and the character of the job. Results of multivariate analysis (multiple regression model) confirmed the statistically significant relationship between the answers and the selected variables (for details, see Table 4).

Males, married persons, blue collar workers, subjects without diagnosed respiratory or cardiovascular disease, and people not living in the vicinity with heavy traffic usually declared to be safe in their daily life. Among those who declared that the environment promoted health were persons without diagnosed respiratory or circulatory disease and subjects not living in the vicinity of the road with heavy traffic. Furthermore, married persons, subjects with a higher level of education, and persons without a history of respiratory or circulatory disease stated to have sufficient money to meet their own needs. The respondents who declared sufficient degree of information required in the daily lives were married, white collar workers, and nonsmokers. Better possibilities to pursue their own interests were more frequently declared by male respondents, persons with higher education level, white collar workers, nonsmokers and subjects without diagnosed respiratory or cardiovascular disease. Better satisfaction with housing was more frequently declared by single (non-married) subjects and those not living near roads with heavy traffic. Indeed, the lower level of satisfaction with health care was more frequent in people living in the vicinity of the 
Table 4. Results of multivariate analysis for relationship between self-declared answers presented in table 3 and particular independent variables describing study group

\begin{tabular}{|c|c|c|c|c|}
\hline Question & Variable & $\begin{array}{l}\text { Regression } \\
\text { coefficient }\end{array}$ & $\begin{array}{c}\text { Statistical } \\
\text { significance }\end{array}$ & $\begin{array}{l}\text { Standard } \\
\text { error }\end{array}$ \\
\hline \multirow{5}{*}{$\begin{array}{l}\text { Q8: Safety in daily life }(1=\text { not, } \\
2=\text { moderately, } 3=\text { much })\end{array}$} & gender $(1=$ female $; 2=$ male $)$ & 0.14 & 0.0007 & 0.04 \\
\hline & marital status $(1=$ married; $2=$ non-married $)$ & -0.17 & 0.0001 & 0.04 \\
\hline & $\begin{array}{l}\text { type of occupational activity }(1=\text { blue } \\
\text { collar; } 2=\text { white collar })\end{array}$ & 0.11 & 0.009 & 0.04 \\
\hline & $\begin{array}{l}\text { vicinity of the road with heavy traffic } \\
(1=\text { yes; } 2=\text { no })\end{array}$ & 0.08 & 0.007 & 0.03 \\
\hline & $\begin{array}{l}\text { recognised respiratory or cardiovascular disease } \\
(1=\text { yes; } 2=\text { no })\end{array}$ & 0.14 & $<0.0001$ & 0.03 \\
\hline \multirow{2}{*}{$\begin{array}{l}\text { Q9: Physical environment is healthy } \\
(1=\text { not }, 2=\text { moderately, } \\
3=\text { much })\end{array}$} & $\begin{array}{l}\text { vicinity of the road with heavy traffic } \\
(1=\text { yes; } 2=\text { no })\end{array}$ & 0.07 & 0.03 & 0.03 \\
\hline & $\begin{array}{l}\text { recognised respiratory or cardiovascular disease } \\
(1=\text { yes; } 2=\text { no })\end{array}$ & 0.09 & 0.01 & 0.03 \\
\hline \multirow{5}{*}{$\begin{array}{l}\text { Q12: Enough money to met own } \\
\text { needs }(1=\text { not, } 2=\text { moderately, } \\
3=\text { mostly })\end{array}$} & gender $(1=$ female; 2 = male $)$ & 0.24 & $<0.0001$ & 0.04 \\
\hline & $\begin{array}{l}\text { marital status }(1=\text { married; } \\
2=\text { non-married })\end{array}$ & -0.22 & $<0.0001$ & 0.05 \\
\hline & education level $(1=$ higher; 2 = lower $)$ & -0.12 & 0.01 & 0.05 \\
\hline & $\begin{array}{l}\text { type of occupational activity }(1=\text { blue } \\
\text { collar; } 2 \text { = white collar })\end{array}$ & 0.15 & 0.002 & 0.05 \\
\hline & $\begin{array}{l}\text { recognised respiratory or cardiovascular disease } \\
(1=\text { yes; } 2=\text { no })\end{array}$ & 0.10 & 0.006 & 0.04 \\
\hline \multirow{3}{*}{$\begin{array}{l}\text { Q13: Availability of information } \\
\text { needed in day-to-day life } \\
(1=\text { not, } 2=\text { moderately, } \\
3=\text { mostly })\end{array}$} & $\begin{array}{l}\text { marital status }(1=\text { married; } \\
2=\text { non-married })\end{array}$ & -0.12 & 0.007 & 0.04 \\
\hline & $\begin{array}{l}\text { type of occupational activity }(1=\text { blue } \\
\text { collar; } 2 \text { = white collar })\end{array}$ & 0.20 & $<0.0001$ & 0.04 \\
\hline & current tobacco smoking $(1=$ yes; $2=$ no $)$ & 0.10 & 0.02 & 0.04 \\
\hline \multirow{5}{*}{$\begin{array}{l}\text { Q14: Opportunity for } \\
\text { leisure activities }(1=\text { not, } \\
2=\text { moderately, } 3=\text { mostly })\end{array}$} & gender $(1=$ female; 2 = male $)$ & 0.19 & $<0.0001$ & 0.04 \\
\hline & education level $(1=$ higher; 2 = lower $)$ & -0.09 & 0.04 & 0.04 \\
\hline & $\begin{array}{l}\text { type of occupational activity }(1=\text { blue } \\
\text { collar; } 2 \text { = white collar })\end{array}$ & 0.14 & 0.002 & 0.04 \\
\hline & current tobacco smoking $(1=$ yes; $2=$ no $)$ & 0.16 & 0.001 & 0.05 \\
\hline & $\begin{array}{l}\text { recognised respiratory or cardiovascular disease } \\
(1=\text { yes; } 2=\text { no })\end{array}$ & 0.09 & 0.01 & 0.03 \\
\hline \multirow{2}{*}{$\begin{array}{l}\text { Q 23: Degree of satisfaction } \\
\text { with conditions of living place } \\
(1=\text { dissatisfied, } 2=\text { moderately, } \\
3=\text { satisfied })\end{array}$} & $\begin{array}{l}\text { marital status }(1=\text { married; } \\
2=\text { non-married })\end{array}$ & -0.29 & $<0.0001$ & 0.04 \\
\hline & $\begin{array}{l}\text { vicinity of the road with heavy traffic } \\
(1=\text { yes; } 2=\text { no })\end{array}$ & 0.08 & 0.008 & 0.03 \\
\hline
\end{tabular}


Table 4. Results of multivariate analysis for relationship between self-declared answers presented in table 3 and particular independent variables describing study group - cont.

\begin{tabular}{|c|c|c|c|c|}
\hline Question & Variable & $\begin{array}{l}\text { Regression } \\
\text { coefficient }\end{array}$ & $\begin{array}{c}\text { Statistical } \\
\text { significance }\end{array}$ & $\begin{array}{c}\text { Standard } \\
\text { error }\end{array}$ \\
\hline \multirow{3}{*}{$\begin{array}{l}\text { Q 24: Degree of satisfaction } \\
\text { with access to health services } \\
(1=\text { dissatisfied, } 2=\text { moderately, } \\
3=\text { satisfied })\end{array}$} & $\begin{array}{l}\text { vicinity of the road with heavy traffic } \\
(1=\text { yes; } 2=\text { no })\end{array}$ & 0.08 & 0.02 & 0.03 \\
\hline & $\begin{array}{l}\text { current job results in deterioration of health } \\
(1=\text { yes; } 2=\text { no })\end{array}$ & 0.08 & 0.01 & 0.03 \\
\hline & $\begin{array}{l}\text { recognised respiratory or cardiovascular disease } \\
(1=\text { yes; } 2=\text { no })\end{array}$ & 0.09 & 0.02 & 0.03 \\
\hline \multirow{4}{*}{$\begin{array}{l}\text { Q 25: Degree of satisfaction with } \\
\text { transport }(1=\text { dissatisfied, } \\
2=\text { moderately, } 3=\text { satisfied })\end{array}$} & gender $(1=$ female; $2=$ male $)$ & -0.11 & 0.02 & 0.05 \\
\hline & $\begin{array}{l}\text { marital status }(1=\text { married; } 2= \\
\text { non-married })\end{array}$ & -0.14 & 0.01 & 0.05 \\
\hline & education level $(1=$ higher; $2=$ lower $)$ & 0.13 & 0.01 & 0.05 \\
\hline & $\begin{array}{l}\text { type of occupational activity }(1=\text { blue } \\
\text { collar; } 2=\text { white collar })\end{array}$ & 0.12 & 0.02 & 0.05 \\
\hline
\end{tabular}

road with heavy traffic, persons with diagnosed respiratory or cardiovascular disease, and those who declared that the current job resulted in deterioration of health. Finally, women, singles (non-married persons), subjects with lower educational levels and white collar workers declared a better level of satisfaction with transport.

The results of U-Mann Whitney test confirmed that the total score obtained for the environmental domain was

Table 5. Results of U-Mann Whitney test for differences in total scoring of assessed environmental domain between particular groups of subjects

\begin{tabular}{lcc}
\hline \multicolumn{1}{c}{ Independent variable } & Median & Statistical significance for U-Mann Whitney test \\
\hline Gender & & 0.006 \\
male & 62.3 & \\
female & 55.6 & $<0.0001$ \\
Marital status & & \\
$\quad$ married & 63.9 & 0.005 \\
$\quad$ non-married & 49.9 & \\
Education level & & \\
higher & 58.8 & $<0.0001$ \\
lower & 54.7 & \\
Type of occupational activity & & \\
$\quad$ white collar & 64.2 & 0.001 \\
blue collar & 56.9 & \\
Current tobacco smoking & & \\
yes & 56.1 & \\
no & 57.4 & \\
\hline
\end{tabular}


Table 5. Results of U-Mann Whitney test for differences in total scoring of assessed environmental domain between particular groups of subjects - cont.

\begin{tabular}{lcc}
\hline \multicolumn{1}{c}{ Independent variable } & Median & Statistical significance for U-Mann Whitney test \\
\hline $\begin{array}{l}\text { Vicinity of the road with heavy traffic } \\
\text { yes }\end{array}$ & 56.4 & $<0.0001$ \\
no & 62.6 & \\
Current job results in deterioration of health & & $<0.0001$ \\
yes & 56.1 & \\
no & 62.8 & $<0.0001$ \\
Recognised respiratory or cardiovascular disease & & \\
yes & 55.8 & \\
no & 62.8 & \\
\hline
\end{tabular}

significantly higher in male population, married persons, subjects with a higher level of education, white collar workers, nonsmokers, persons not residing in the vicinity of the road with heavy traffic, persons without diagnosed respiratory or circulatory disease and those whose job did not cause health deterioration. Table 5 lists the detailed results.

The lowest scores of the environmental domain of quality of life were obtained for workers who declared poor health status (Figure 1). The ANOVA test confirmed statistically significant differences between the three groups of health status.

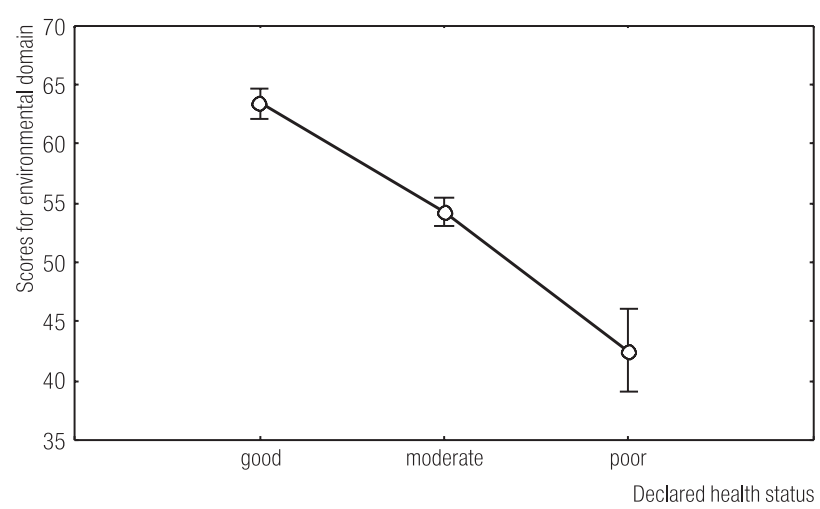

Fig. 1. Differences in scores for the environmental quality of life domain

Table 6. Results of multivariate analysis for relationship between total scoring in environmental domain and particular independent variables describing subjects, regression coefficients and their statistical significance

\begin{tabular}{|c|c|c|c|}
\hline Independent variable & $\begin{array}{l}\text { Regression } \\
\text { coefficient }\end{array}$ & $\begin{array}{c}\text { Statistical } \\
\text { significance }\end{array}$ & $\begin{array}{c}\text { Standard } \\
\text { error }\end{array}$ \\
\hline Gender $(1=$ female, $2=$ male $)$ & 0.05 & 0.05 & 0.02 \\
\hline Marital status (1 = married, 2 = non-married $)$ & -0.12 & $<0.0001$ & 0.02 \\
\hline Education level (1 = higher, 2 = lower $)$ & 0.01 & 0.6 & 0.03 \\
\hline Type of occupational activity ( 1 = blue collar, 2 = white collar $)$ & 0.13 & $<0.0001$ & 0.03 \\
\hline Current tobacco smoking $(1=$ yes, $2=$ no $)$ & 0.05 & 0.05 & 0.02 \\
\hline Living in the vicinity of the road with heavy traffic $(1=$ yes, $2=$ no) & 0.05 & 0.05 & 0.02 \\
\hline Declared health status $(1=$ good, $2=$ moderate, $3=$ poor $)$ & -0.035 & $<0.0001$ & 0.03 \\
\hline Current job results in deterioration of health $(1=$ yes, $2=$ no $)$ & 0.03 & 0.1 & 0.02 \\
\hline $\begin{array}{l}\text { Ever diagnosed respiratory or cardiovascular disease } \\
\qquad(1=\text { yes, } 2=\text { no })\end{array}$ & 0.01 & 0.6 & 0.02 \\
\hline
\end{tabular}


Finally, the results of multivariate analysis confirmed the significant effect of gender, marital status, type of occupational activity, and declared health status on the resultant scores in the environmental domain of quality of life.

\section{DISCUSSION}

The obtained results confirmed the importance of marital status, type of occupational activity, and declared health status to the environmental domain of quality of life in economically active inhabitants of the Silesian Agglomeration. Similar findings were obtained in a study of total quality of life (where we assessed four domains of quality of life: somatic, psychological, social and environmental). These data were published earlier in the Medycyna Pracy [7]. The environmental domain of life embraces such aspects of life as safety, financial situation, the ability to pursue one's interests, housing, health care facilities, and communications. The best level of quality of life in the environmental domain was characteristic for married person, white collars, and person who declared the best health status. Furthermore, it should be noted that female gender, current tobacco smoking and persons living in the vicinity of the road with heavy traffic were associated with lower quality of life. The resultant value of statistical significance was 0.05 .

Scoring for the environmental domain was one of the lowest among all the evaluated areas of quality of life (Table 1). The total score in this domain, 57.6 \pm 14.6 , was significantly lower than that reported in studies published by other authors $[2,8]$. The results of testing the quality of life for the two populations with a total number of 1724 subjects present standards for each four assessed domains of quality of life. According to the quoted data, the average number of points for the environmental domain ranged: 69.9-75.0 for people aged 40-49 years, 73.7-80.3 for people aged 50-59 years and 74.3-77.9 for people aged 60-69 years [2].

As indicated above, the environmental domain scoring was constant across all age groups. Data for the population of people aged 60 or more in Turkey also indicate better quality of life in the environmental domain than in our observation [8]. The resultant scores, $66.5 \pm 17.2$, were significantly higher than in our study. The observed differences in scores in our study and that quoted above could be the result of demographic, economic, or religious differences between the compared populations. With this explanation, we suggest that quality of life in highly developed countries is better than in the developing countries, as identified by the Human Development Index (HDI). The mean value of scoring in environmental domain in various countries was: $64.9 \pm 16.1$ for populations in countries with the highest level of HDI (for example Norway and Germany) and 55.2 \pm 16.3 with medium level of HDI (for example Bulgaria and Turkey), respectively [9]. Recent data rank Poland rather among countries with medium HDI [10]. Similar results were obtained in a study of Lithuanians, the mean score for environmental domain was 54.6 \pm 10.8 [11]. Considering this evidence, it should be noted that our results were typical for countries with similar level of Human Development Index.

An important observation is the significant relationship between the environmental domain of quality of life and marital status of respondents. The higher scores (better quality of life) were those of married persons than single respondents. The impact of marital status on the declared level of quality of life was also the subject of the study among the elderly [12]. The authors showed that married people rather than divorced had a better quality of life. Similarly, a better quality of life was observed in persons who were married than non-married in the study of patients with rheumatoid arthritis [13], diseases of the cardiovascular system [14], and people after stroke [15]. The authors argue that for those patients, support from the family is essential to ensure better quality of life. It turns out that it is also important for the healthy and economically active population.

Observations on the positive impact of higher education on quality of life of the respondents are consistent with 
the results already published for a population of women aged 45-60 years, in the Silesia province [4]. Although the studies used different tools, the results are similar in that they confirm the belief that standard questionnaires can ensure authoritative measurement of quality of life. Strong correlation between higher levels of education and a better quality of life was also demonstrated in studies of older people (aged 65-74 years) under long-term care in rural provinces [12] and in the study of patients aged 2379 years diagnosed with rheumatoid arthritis [13]. It is evident that a person's level of education is a strong determinant of quality of life in current state. In our study, good health was reported by almost every second respondent (42.9\%) and poor health was indicated only by $5.3 \%$ of the respondents. As demonstrated, both a better quality of life and better health were more frequently associated with people of higher educational level. This valuable information indicates that the direction of the changes taking place in the Polish education that promotes lifelong learning [16] is valid also for the health condition of society.

The percentage of people who declared in our study having good quality of life was $64.3 \%$. On the contrary, only $5.5 \%$ felt their quality of life was poor. These results are consistent with data published in a 2010 report, where very good health and well-being were reported by $68 \%$ of people aged 45-54 and 47\% of people aged 55-64 [17]. The quoted report also indicates that the level of satisfaction is much higher in Poland than in other European Union countries (55\% in France, 54\% in Spain, 52\% in Germany). These differences could be attributed to the composition of the test groups. For example in our study we had economically active, 45-60 years old individuals. However, the data from other studies used groups at different age as well as the general population.

An important issue is the impact of work on the formation of the quality of life. Our results have highlighted that the nature of the work is important for a person's well-being and health. The obtained data showed that the environmental quality of life was significantly better in white- than bluecollar workers. The same was true in the case of the declared state of health; the percent of white-collar workers with good health was significantly higher than that of bluecollar workers ( $48.2 \%$ vs. $35.2 \%$, respectively). It is crucial not to ignore the issue of education, which is an important determinant of the nature of the employment and proved to be the dominant variable in the regression analysis.

The quoted 2010 report showed that one in ten examined Pole was satisfied with work. However, ranking of the importance of work for the assessed quality of life decreases with age. Jobs and career turned out to be important for good health and well-being of $77 \%$ of respondents aged 45-54 and only $41 \%$ of those aged 55-64 [17]. Daily working time is also vital for the quality of life. It is estimated that Poland belongs to countries where working time of $48 \mathrm{~h}$ per week is exceeded most frequently [18]. This aspect was not examined in our work, although a detailed analysis of the collected data suggests that only $18.9 \%$ of respondents felt that the work done resulted in a deterioration of health status. Among our respondents, the most frequently declared problems were: stress (68 workers) and excessive effort causing pain in bone and muscle (31 workers). It should be noted that the major determinants of health and quality of life in economically active population include non-occupational factors, such as: family, network and community or society-level aspects. The systematic review of published data has shown that the nonoccupational domain is a largely underinvestigated area of workers' mental health research [19].

The highest levels of dissatisfaction in the environmental quality of life were closely related with both poor financial position and limited access to health services. In both cases, significantly better quality of life was declared by people without any diagnosis of respiratory or cardiovascular disease. Thus, it is confirmed that healthier people declared a better quality of life. The results of an earlier study documenting the quality of life in Europe suggest 
that the declared quality of health services (scored from 1 to 10) was one of the lowest in Poland. The values of average ratings of quality services were 5.0 in Poland, 7.8 in Austria, 7.7 in Belgium [20]. Similarly, Poland has one of the lowest indicators describing the economic situation of inhabitants. Gross domestic product (GDP) per capita in terms of purchasing power standard (PPS) in 2006 was 52 in Poland, 128 in Austria and 120 in Belgium [21]. A large proportion of people report difficulties in accessing health services and have concerns about the quality of health and care services available. These findings are very important for setting priorities in public health and social policies.

The last of the issues examined in our study was the impact of the residence environment on the declared quality of life. It was found that an important factor for a better quality of life was to live far from heavy traffic. With a relatively high percentage of people declaring full satisfaction with the conditions of the living place (73.6\%) it was noted that this level of satisfaction is significantly higher in persons not living in the vicinity of the road with heavy traffic (Table 4). In our opinion, the level of dissatisfaction is related to a significant role in the oversize noise exposure and air pollution from the road transport. It seems that the current European efforts to reduce car traffic in city centers [21-23] are also an important option for residents of urbanized areas, which include the Silesian Agglomeration. Local and regional authorities can play an important role in reducing environmental hazards to improve the quality of life of the vulnerable population.

\section{CONCLUSIONS}

While the major determinants of environmental quality of life in economically active population living in the industrial agglomeration (Silesian Agglomeration) include non-occupational factors, such as marital status and current health condition, a significantly better quality of life was associated with being white-collar worker and not living in the vicinity of a road with heavy traffic. These observations may be useful for future activities intended to improve health and the quality of life of workers.

\section{REFERENCES}

1. Lucas-Carrasco R. The WHO quality of life (WHOQOL) questionnaire: Spanish development and validation studies. Qual Life Res 2012;21(1):161-5. DOI 10.1007/s11136-0119926-3.

2. Hawthorne G, Herman $\mathrm{H}$, Murphy $\mathrm{H}$. Interpreting the WHOQOL-BREF: Preliminary population norms and effects sizes. Soc Indicators Res 2006;77:37-59. DOI 10.1007/s11205-0055552-1.

3. European Environment Agency. The European environmentState and outlook 2010. Synthesis. Copenhagen: EEA; 2010. p. 91-113.

4. Kowalska M, Marcinkowska U, Jośko J. Occupational satisfaction and quality of life in women aged 45-60 years in the Silesia voivodeship. Med Pr 2010;61(3):277-85 [in Polish].

5. WHO Quality of Life-BREF (WHOQOL-BREF) [cited 2009 Oct 19]. Available from URL: http://www.who.int/ substance_ abuse/research_tools/whoqolbref/en.

6. WHOQOL-BREF. Introduction, administration, scoring and generic version of the assessment. Field Trial Version. Geneva: WHO; 1996.

7. Kowalska M, Humeniuk M, Danso F, Kułak E, Arasiewicz H. Quality of life of occupationally active people, aged 45-60, living in the Polish industrial region (Silesian Agglomeration). Med Pr 2011;62(5):455-63 [in Polish].

8. Bodur S, Dayanir Cingil D. Using WHOQOL-BREF to evaluate quality of life among Turkish elders in different residential environments. J Nutr Health Aging 2009;13(7):653-6.

9. Skevington SM. Qualities of life, educational level and human development: an international investigation of health. Soc Psychiatry Epidemiol 2010;45:999-1009. DOI 10.1007/s00127009-0138-x. 
10. Human Development Report 2009. Overcoming barriers: Human mobility and development. New York: United Nations Development Programme (UNDP) [cited 2011 Jan 21]. Available from URL: http://hdr.undp.org/en/media/ HDR_2009_EN_Complete.pdf.

11. Baceviciene M, Reklaitiene R. Psychometric properties of the World Health Organization Quality of Life 100 questionnaire in the middle-aged Lithuanian population of Kaunas city. Medicina (Kaunas) 2009,45(6):493-500 [cited 2011 Aug 1]. Available from URL: http://www.medicine.kwnu.lt.

12. Fidecki W, Wysokiński M, Wrońska E, Walas L, Sienkiewicz Z. Life quality of elderly people from rural environment provided with long-term care. Probl Hig Epidemiol 2011;92(2): 221-5 [in Polish].

13. Jankowska B, Uchmanowicz I, Polański J, Uchmanowicz B, Dudek K. Clinical and sociodemographic factors determining quality of life in rheumatoid arthritis (RA). Family Med Prim Care Rev 2010;12(4):1027-34 [cited 2011 Jul 28]. Available from URL: http://www.familymedreview.org/ files/2010/pdf_042010/2_original_papers_1027_1048.pdf [in Polish].

14. Kawecka-Jaszcz K, Klocek M, Tobiasz-Adamczyk B, editors. Quality of life in diseases of the cardiovascular system. Methods of measurement and clinical significance. Poznań: Termedia; 2006 [in Polish].

15. Jaracz K, Kozubski W. Quality of life after stroke - clinical, functional and socio-demografic correlates. Udar Mozg Probl Interdysc 2001;3(2):63-70 [cited 2011 Jul 28]. Available from URL: http://www.um.viamedica.pl/darmowy_pdf. phtml?indeks $=6$ \&indeks_art $=11$ [in Polish].

16. Chmielecka E, editor. The autonomy of the university curriculum. Qualifications framework for higher education.
Warszawa: Ministry of Science and Higher Education 2010 [in Polish].

17. Philips Index 2010. Quality of Life Survey Poles [cited 2011 Jul 28]. Available from URL: http://www.egospodarka.pl/ pliki/raport-philips-index-2010.pdf [in Polish].

18. Żołnierczyk-Zreda D. Long working hours and mental health and quality of life - review of research. Bezp Pr 2009 [cited 2011 Aug 1]. Available from URL: http://www.ciop.pl/ 35103 [in Polish].

19. Beauregard N, Marchand A, Blanc ME. What do we know about the non-work determinants of workers' mental health? A systematic review of longitudinal studies. BMC Public Health 2011;11:439-53 [cited 2011 Aug 16]. Available from URL: http://www.biomedcentral.com/14712458/11/439.

20. Second European Quality of Life Survey Overview. Dublin: European Foundation for the Improvement of Living and Working Conditions; 2007 [cited 2011 Aug 16]. Available from URL: http://www.eurofound.europa.eu/pubdocs/2009/02/en/2/ EF0902EN.pdf.

21. Tonne C, Beevers S, Armstrong B, Kelly F, Wilkinson P. Air pollution and mortality benefits of the London Congestion Charge: spatial and socioeconomic inequalities. Occup Environ Med 2008;65(9):620-7.

22. Transfer Guidebook. Transferring a traffic environment model chain to an European Region. Final version. Citeair 2007 [cited 2011 Aug 17]. Available from URL: http://www.citeair. rec.org/downloads/Products/TransferringTraffic-EnvModels Chain.pdf.

23. Polis Network. European cities and regions networking for innovative transport solutions [cited 2011 Aug 17]. Available from URL: http://www.polisnetwork.eu/working-groups/wgenvironement-and-health-in-transports.

This work is available in Open Access model and licensed under a Creative Commons Attribution-NonCommercial 3.0 Poland License - http://creativecommons.org/ licenses/by-nc/3.0/pl/deed.en. 